\title{
A Comparison of the Use of Strategic Thinking Skills of Aspiring School Leaders in Hong Kong, Malaysia, Shanghai, and the United States: An Exploratory Study
}

\author{
John Pisapia (Corresponding Author) \\ Florida Atlantic University \\ Boca Raton, Florida 33431 \\ E-mail: jpisapia@fau.edu \\ Nicholas Sun-Keung Pang \\ The Chinese university of Hong Kong \\ E-mail: nskpang@cuhk.edu.hk
}

Tie Fatt Hee

University of Malaya

E-mail: tiefh@um.edu.my

Ying Lin

China Executive Leadership Academy Pudong

E-mail: ylin@celap.org.cn

John D. Morris

Florida Atlantic University

E-mail: jdmorris@fau.edu

\begin{abstract}
Cognition is the way we use mental skills to acquire knowledge, manipulate ideas, and process new information and beliefs. The Strategic Thinking Questionnaire (STQ), which measures three such skills - systems thinking - reframing reflection, was used to collect data from students preparing for school leadership roles at four universities in the United States (USA), Malaysia, Hong Kong, and Shanghai. It was thought that the use of these skills might vary from country to country because of western and eastern cultural norms. Based on self-reported data from 328 educators preparing for school leadership roles we concluded that the use of strategic thinking skills were found in all locations but the variance in their use is more a function of age of respondents, and gender rather than location. These findings have implications for training, professional development, and selection of aspiring leaders.
\end{abstract}

Keywords: Strategic thinking, Reflection, Systems thinking, Reframing, School leadership preparation, Thinking habits

\section{Introduction}

The ability to interpret and make meaning of discreet and seemingly unrelated events is a hallmark of today's successful leader. This ability should help leaders think strategically by understanding, identifying, predicting, responding, and adapting to opportunities and challenges confronting them. The need for school leaders to think strategically has gone unchallenged as the world reacts to the effects of globalization, which are creating a profound challenge for all organizational leaders. In 2006, Pisapia noted that leaders who find themselves in such messy, chaotic, complex environments fail because they are trained in and rely upon a linear thinking mindset that does not work in situations characterized by ambiguity and complexity. They are unable to identify critical societal and institutional forces 
influencing their environment and thus do not connect their organizations to the current major themes associated with success. Their concept of change is also linear; therefore, they overuse quantifiable parameters in the change process and seek to rationally plan their way to success. By failing to consider that their organization is dependent upon the actions and views of other organizations and individuals; they do not connect with significant forces on their critical paths of success. Schreyogg and Noss (2000) and Weick and Quinn (1999) support the claim that there is an over reliance on linearity which does not fit with today's realities of 'fast and furious' change. This environmental change requires leaders who can add strategic thinking capabilities to their repertoire of the more common analytical capabilities long taught in our management schools.

Strategic thinkers work from a mental model of the complete system. This strategic mindset incorporates an understanding of both the external and internal context of the organization. Henry Mintzberg (1994, p. 10) sees strategic thinking as a synthesizing process utilizing intuition and creativity whose outcome is "an integrated perspective of the enterprise." From this integrated perspective, strategic thinking challenges existing assumptions and action alternatives, potentially leading to new and more correct ones.

Strategic thinking is creative, critical, and analytical although accomplishing all types of thinking simultaneously is difficult, because of the requirement to suspend critical judgment. When applied correctly, strategic thinking enables the leader to (a) recognize interdependencies, interrelationships and patterns, and (b) make consequential decisions using both powers of analysis and intuition. Chilcoat (1995) and Pisapia, Reyes-Guerra and Coukos-Semmel (2005), for example, suggest that effective leaders demonstrate more complex mental skills than ineffective leaders. Leithwood and Steinbach (1992) believe that efforts to improve the effectiveness of education may be more productive if more consideration was given to improving the quality of thinking and problem solving abilities of administrative and teachers rather than simply focusing on actions or behaviors.

Cognition is the way thinking occurs. Mental or cognitive skills enable the acquisition of knowledge by manipulating ideas and processing new information and beliefs in our minds. Information, memory, reasoning, application of schemas and biases, making attributions and thinking-through a problem are examples of cognitive skills. Some people take mental shortcuts, acting on what we expect to see.

\section{The Literature}

The literature identifies many cognitive skills such as: chunking (Agor, 1988; Newell \& Rosenbloom, 1981; Simon, 1957, 1999), cognitive reduction (Simon, 1957), cognitive heuristics (Stanwick, 1996), cognitive maps/schemas (March \& Simon, 1958; Simon 1957; Stanwick, 1996), mental imagery (Anthony, Bennet, Maddox, \& Wheatley, 1993; Stanwick, 1996), creativity (Depree, 1989). These shortcuts are useful when making quick decisions such as in single loop learning and problem solving to react to circumstances based on taken for granted values, goals, frameworks. The emphasis is on techniques and making the organization more efficient by detecting and correcting error (Usher \& Bryant 1989).

At other times, the outcomes being sought are strategic and the need is to learn to see past the façade or assumptions of an issue to examine the underlying situation to understand the psychology and systemic issues present in the situation. The emphasis is on techniques that make the organization more efficient by detecting and correcting error. These times call for other mental tools such as: mental models and schemas (Riedel, Morath, \& McGonigle, 2000; Senge, 1990; Weick, 1995;), critical thinking (Baron, 1994; Cohen, Thompson, Adelman, Bresnick, Shastri, \& Riedel, 2000; Halpren, 1996; Riedel et al., 2000), pattern recognition (Cohen et al.2000; Simon, 1957, 1995), reframing (Bolman \& Deal, 1994; Morgan, 1986), reflection (Argyris \& Schön, 1978, 1996; Dewey 1933; Schön, 1983), and systems thinking (Senge, 1990). One way to do this is to become a master of asking powerful questions.

Considering that, this listing is not exhaustive, some have argued (e.g., Perkins, 1995) there may be too many strategies for leaders to remember, consider, select, and apply. However, regardless of the architecture presumed to underlie human cognition, the fact is that leaders must retrieve, activate, and/or recreate knowledge to influence actions and perceptions of followers. As Pisapia (2006) suggested a strategic agile mindset is indispensible for modern leaders. Looking for a more parsimonious set of skills, Pisapia and Reyes-Guerra built on the earlier work of Argyris, Schön, (1978) and Senge's (1990) work to identifying components of strategic thinking. They identified three cognitive skills (systems thinking, reframing and reflection) that enable leaders to think strategically and theorized that they were potential distinguishers between successful and less successful leaders. Thus, they are important skills Universities should teach and aspiring leader should learn.

\section{The Strategic Thinking Skills}

We begin by defining the three strategic thinking skills that appear to be related to leader success (Pisapia, Reyes-Guerra \& Coukos-Semmel, 2005; Pisapia, Reyes-Guerra \& Yasin 2006). These three skills assist leaders in (a) reframing situations so they become clearer and more understandable; (b) reflecting and developing theories of practice which guide actions; 
and, (c) thinking in more holistic ways. They also aid leaders in seeing events and problems in terms of concepts, which are useful ways of thinking effectively about problems.

Fluency in multiple frames is a basic skill for postmodern leaders. It is critical for them to make their dominant frames explicit and to widen their frame repertoire. Pang and Pisapia (2006) suggest that leaders must frame and place all situations in context. Framing is a cognitive process that helps individuals gather and organize information and create knowledge. It involves sorting and interpreting the meaning of new information, events, and experiences. Framing imposes provides a language for analysis of behavior in which aspects of situations are interpreted through multiple lenses. Typically, individuals reach for frames when trying to understand new, complicated events and how communications, goals, and initiatives could be perceived. However, the manner in which a leader frames a situation is crucial to his or her understanding and public reasoning.

Reframing is a conscious effort by leaders to switch attention across multiple perspectives in order to generate new insights and options for actions. The goal is to produce usable knowledge by rotating through appropriate conceptual models for the activities and events observed. This process can overcome Bolman and Deal's (1991) assertion that using singular frames filter out some things and allow others things to pass through quickly. "The ability to reframe experiences enriches and broadens a leader's repertoire and serves as a powerful antidote to self entrapment” (pg 4). Reframing a problem involves a conscious effort to size up a situation using multiple lenses. Bolman and Deal assert that:

Managers who master the ability to reframe report a liberating sense of choice and power. They are able to develop unique alternatives and novel ideas about what their organization needs. They are able to tune in to people and events around them and less often startled by organizational perversity, and they learn to anticipate the turbulent twists and turns of organizational life. The result is managerial freedom - and more productive, humane organizations. (p. 17)

Reframing in this study refers to leaders' ability to switch attention across multiple perspectives, frames, mental models, and paradigms in order to generate new insights and options for actions. It enables one to sort through problems and opportunities, to see problems in ways that allow them to map out different strategies, and identify trends before others see them. Someone with this ability would be able to recognize when information is presented from only one perspective. They would also demonstrate a willingness to seek different viewpoints on complex problems, ask those around them what they think is changing, and discuss solutions with critics and challengers as well as supporters.

Reflection is a cognitive skill that involves careful consideration of any belief or practice that promotes understanding of situations and then applies the newly gained knowledge to these situations. It relies on subjecting evidence, perceptions, and experience to critical scrutiny, but suspending critical judgment, in order to make sense and meaning of situations prior to weaving the thinking into a theory of practice. By reflecting on both successes and failures, leaders begin to unpack the assumptions and values that lie beneath rules, regulations, and skills in work and everyday life. This constant effort of reevaluation and interpretati2on is an integral part of how leaders make sense of situations. Even though the leader is without all the information needed, the use of reflection will offer the best possible options for action and prediction. Senge (1990) uses the three types of reflection when he describes professional practice based on reflective thinking in terms of levels. Senge says,

The first level is technical reflection, which is concerned with examining the efficiency and the effectiveness of means to achieve certain ends. The second level, practical reflection, involves examining not only the means but also the ends, questioning the assumptions and the actual outcomes. The third level is critical reflection, which considers the moral and ethical issues of the social compassion and justice along with the means and the ends, encompassing the first two levels. (p.2)

Of the three types, critical reflection is the most necessary for transforming oneself and ones organizations. As Mezirow (1990, pp. 12-13) points out, 'We become critically reflective by challenging the established definition of a problem being addressed, perhaps by finding a new metaphor that reorients problem-solving efforts in a more effective way.

Argyris and Schön (1978) have a similar way of describing reflective thought. They differentiate between single and double loop learning. They describe single-loop learning as a reaction to circumstances based on taken for granted values, goals, frameworks, and to a significant extent, strategies are taken for granted. They point out that, in single loop learning, reflection is focused on making the organization more efficient and the detection and correction of error. The emphasis is on techniques and making them more efficient (Usher and Bryant 1989). In single loop learning, the assumptions governing a situation are not questioned. If reflection occurs in this situation, it is simply to make the organization more efficient. They just look for another strategy to achieve its present objectives.

Transformative learning is accomplished through double loop learning which is applied when coping will not be sufficient to gain organizational fitness. It is used to change the organization's mindset; its core set of principles, beliefs, and norms. Double loop learning, which is deeper than single loop learning, emerges when members review new 
environmental challenges and critique current organizational assumptions and ways of doing business to determine if new responses and new basic assumptions need to be embraced to gain organizational fitness.

Reflection, in this study, refers to leaders' ability to weave logical and rational thinking together with experiential thinking through perceptions, experience, and information to make judgments as to what has happened and then creates intuitive principles that guide future actions. In reflection, one uses perceptions, experience, and information to make judgments as to what has happened in the past and is happening in the present to help guide their future actions. Someone with this ability would be able to understand the past, present, and perhaps the future by recognizing why certain choices worked and others did not. They would demonstrate a willingness to question their assumptions and test whether their behaviors actually result in desired outcomes. It enables one to use perceptions, experiences, and knowledge to understand situations, how to think about them and inform action.

Systems' thinking requires that the leader understands that he or she is part of a feedback process, not standing apart from one. This understanding represents 'a profound shift in awareness' that there is connectivity between members of organizations that influences the way a system works. The perspective gained from looking at feedback in this way 'suggests that everyone shares responsibility for problems generated by a system' (Senge 1990, p.78).. This feedback perspective becomes especially significant when leading organizations. Organizations are always involved in skills that determine their output and direction. Senge (1990: p. 87) recommends that in order to understand a balancing feedback process the systems thinker must 'start at the gap - the discrepancy between what is desired and what exists... then look at the actions being taken to correct the gap'. The leader must then translate the understanding into action. Senge (1990: p. 114) emphasizes that the 'bottom line of systems thinking is leverage - seeing where actions and changes in structures can lead to significant, enduring improvements'.

Systems thinking in this study refer to leaders' ability to see systems holistically by understanding the properties, forces, patterns, and interrelationships that shape the behaviors of the systems which provide options for actions. This definition requires that leaders think holistically, defining the entire problem by extracting patterns in the information one collects before breaking the problem into parts. This capability enables someone to understand how facts relate to each other. It also enables them to seek the cause of a demand for products or services that their organization produces before taking action to meet the demand and seek feedback to help individuals and the organization self correct.

\section{Purpose}

This paper reports an exploration into the use of foundational thinking skills - systems thinking, reframing, and reflection -needed for strategic thinking - by educators preparing for department chair, assistant principal and principal roles in the USA, Hong Kong, Malaysia, and Shanghai. The study's purpose was limited to answering the following two questions:

(1) Do students preparing for leadership roles in the USA, Hong Kong, Malaysia, and Shanghai use strategic thinking skills differently?

(2) How do contextual variables of location, age, and gender affect the use of strategic thinking skills?

\section{Methods}

The examination of the cognitive aspects of leadership development has largely gone unnoticed in the research on leadership. Thus, creating a vacuum in an area of leadership identification and development that has both been recognized over 70 years ago in seminal works regarding reflection (Dewey, 1933, Argyris \& Schön, 1978) and brought to the forefront over 10 years ago concerning reframing (Morgan, 1986; Bolman \& Deal, 1991) and during the last 35 years concerning systems thinking (Bertalanffy, 1968; Senge, 1990). Hence, we conceived of this data collection as non-experimental and exploratory since modest research has been conducted on these variables.

\section{Sample}

For this study, a purposeful sample of 328 English-speaking students studying at The Chinese University of Hong Kong, University of Malaya, China Executive Leadership Academy, and Florida Atlantic University was drawn for analysis. The University of Malaya provided two subsamples; one from Kuala Lumpur $(\mathrm{n}=52)$ and the other from Sarawak on the island of Borneo $(\mathrm{n}=59)$. Table 1 presents the demographic data for the participants in the study by site.

[Table 1 about here]

As seen in Table 1, Hong Kong (HK) provided $31 \%$ of the sample. All other sites produced from 16 to $20 \%$ of the sample. Females composed $59 \%$ of the total sample. Their prevalence was apparent in the USA and Shanghai samples. Males were more prevalent in the Borneo sample.

The Shanghai students were the youngest and still in the process of acquiring their bachelors degree in education. The USA sample was younger than the HK and Malaysian samples. Eighty four percent of the USA sample fell into the 20-44 age groupings. Ninety eight percent of the HK and Borneo samples fell in the 35-54-age groupings. One hundred percent of the Kuala Lumpur (KL) sample fell in the same age categories. 


\section{Instrumentation}

The Strategic Leadership Questionnaire: STQ@ v4 (Pisapia \& Reyes-Guerra 2008) was used to collect the data for this study. Version4 is six pages long and consists of forty-eight Likert type questions. The STQ provides an assessment of three skills - systems thinking, reflection - reframing - thought to be important to useful in self-assessment and for development in classes and/or seminars. The STQ (C) asks respondents how often they use the skills when confronted with problems. It is only available in a self-format since it is felt that only the test taker can describe how often they employ the skills. Typically, participants return the instrument directly to the researchers or seminar facilitator. The STQ takes approximately fifteen or twenty minutes to complete and is capable of being either self or computer scored.

The original STQ@ developers (Pisapia, Reyes-Guerra, \& Coukos-Semmel (2005) reviewed the literature and then defined the three cognitive skills. Using the definitions as guides, they wrote statements describing skills required to think in systems, reframing, and reflection terms. A panel of five experts knowledgeable about strategic thinking reviewed the resulting 180 items. They sorted the statements into the three categories. In an iterative fashion, the statements were modified or discarded following lengthy discussions and repeated feedback sessions between the panel and researchers. Items on the STQ are cast on a five-point Likert scale. A higher value represents greater use of a cognitive skill, as noted below:

$1=$ Almost Never uses

$2=$ Rarely uses

$3=$ Sometimes uses

$4=$ Frequently uses

$5=$ Almost Always uses

Following each administration (4 now) of the STQ, the items were subject to empirical analyses followed by discussions conducted in an iterative fashion until the statements were representative of the strategic thinking construct. Ongoing analysis and refinements in the instrument continue, with a database involving 3,000 respondents. Table 2 presents the means, standard deviations and Cronbach Alpha's for the STQ Version3 and Version4.

[Table 2 about here]

In STQv3, the rank order of skill usage is systems thinking (3.55), reframing (3.45), and reflecting (3.48). Based on the mean scores, it was expected that systems thinking would be the skill most frequently used, followed by reframing. Internal reliabilities of Version3 were assessed through the standardized Cronbach's Alpha. A .70 value generally considered to indicate a sufficient reliability by classical psychometric authorities (Nunnally, 1978; Peterson, 1994). Reliability statistics for the STQv3 (based on approximately 643- ratings by a multi-sector sample of managers in business and education) where computed. Internal reliabilities ranged between .71 and .77 for the subscales and .89 for the total scale. Other studies have found similar reliabilities. For instance, Pisapia, Reyes-Guerra \& Coukos-Semmel (2005) reported reliabilities ranging from .77-.83 on subscales and .91 for the scale.

As seen on Table 2, internal reliabilities (Cronbach Alphas) on the STQv4 are higher than Version3 on all scales except reflecting. This may be explained by in difference in number of items on the scale from v3 to v4. They range between .74 and .87 for the subscales and .93 for the scale meeting the .70 standard. Additionally, the rank order of the means on the subscales reveal that the systems thinking is the cognitive skill most frequently used as expected from the version 3 and earlier administrations. However, the reflecting skills (3.66) surpassed reframing (3.43) as the second most used skill. Thus, the rank ordering of means among the v4 sub scales is exactly the same v3 subscales except that they were used more often by this sample.

The STQ was originally developed from an interpretation of the literature on strategic thinking as being composed of systems thinking, reframing and reflection. The literature portrayed reframing as part of reflection. The researchers believed that reframing was an important skill in its own right. Hence, it was originally extracted and tested as a unique variable from reflection in order to give it emphasis. The skills embodied in systems thinking, reframing and reflection reveal the participants ability to think flexibly, conceptually and strategically. The interpretation of these dimensions provides participants with a deeper understanding of their own mental processing skills. However, in daily use, the three cognitive skills overlap considerably; our experience is that they are best taught singularly. Theoretically, the STQCV4 measured the participant's capability to think strategically. It included 17 items from systems thinking, 14 from reframing, and 14 reflection items. The STQv3 when subjected to factor analyses produced one predictive factor - the overall strategic thinking score (Pisapia, Reyes-Guerra, \& Yasin 2006).

Version4 was subjected to a principle axis factoring method with iterative communality estimation and oblimin with Kaiser Normalization rotation. The two factors (systems thinking and reflection) with Eigenvalues greater than 1.0 reported in Table 3 accounted for 52 percent of the variance. Values less than the 10 threshold were suppressed and not reported on the table. One might argue that the difference may not be in level or variance on the factors derived with the 
complete data set, rather, that the factors themselves are different across cultural groups. With these data, the point may be a good one, but not enough subjects were available to consider cross-cultural factor agreement though separate factor analyses.

[Table 3 about here]

By factoring the 48 questions on the STQ@v4, two interpretable factors that are consistent with the definitions of systems thinking and reflection were obtained. This result is inconsistent with the hypothesized three subscales of the STQ but consistent with the literature on the subject. The two factors (Systems Thinking and Reflection) will be the guiding framework for continued research and teaching of strategic thinking skills until empirical analyses confirms the reframing subscale.

\section{Data Collection}

The STQv4 was administered in different ways in each of the locations. The USA English version4 was used in the USA and Borneo data collections. In KL and Shanghai, the English version was translated into Malay and Mandarin. Local researchers translated the STQ and then a colleague retranslated it back to English. They shared their English translations with the USA developers and through an iterative process; the translated versions came closer to the USA version4. In Hong Kong, the local researcher presented the English version4 in hard copy but answered questions from students concerning the meaning of certain English words. The HK sample was considered English literate but not all were proficient which could have impacted the HK results.

\section{Results and Discussion}

Two research questions guided the data collection and analyses.

Research Question 1: Do students preparing for leadership roles in the USA, Hong Kong, Malaysia, and Shanghai use strategic thinking skills differently?

Research Question 2: Do contextual variables of age, gender affect the use of strategic thinking skills?

The data are displayed and analyzed with descriptive statistics and multiple univariate analyses of variance. An Alpha level of 0.05 was set for all statistical tests. Eta ${ }^{2}$ was used to investigate effect sizes.

\subsection{Use of Strategic Thinking Skills}

The use of strategic thinking skills among students preparing for school leadership roles was investigated by comparing the means for participants at each location. As seen on Table 4, the rank order use of strategic thinking skills is Borneo, USA, Kuala Lumpur, Hong Kong, and Shanghai.

\section{[Table 4 about here]}

The two highest scoring locations (Borneo and USA) both administered the English Version4 of the STQ. Participants at these locations were dissimilar on age and gender variables. Borneo participants were overrepresented by males (73\%) and the USA participants were overrepresented by females (86\%). While males in Borneo and females in the USA represent a greater proportion of those preparing for leadership roles, both groups were overrepresented in each sample. The USA sample was younger than the Borneo sample but all participants were in graduate programs. Eighty four percent of the USA sample fell into the 20-44 age groupings. Ninety eight percent of the Borneo samples fell in the 3554-age groupings.

In KL, the STQ was translated and administered in Malay. The results were consistently at the middle of the rank order of means. There was a more even distribution of males $(54 \%)$ and females $(46 \%)$ than in the USA and Borneo locations. On the age variable, ninety percent of respondents were in the 45-54 age group compared to the sample mean of forty two percent.

In Shanghai, the STQ was translated into Mandarin and the match with the English version achieved high fidelity. However, the results from this location were consistently low in comparison to the other locations. The participants at this sites were mostly female (88\%) and all fell in the 20-25 age group.

Table 5 presents the relationship between location and strategic thinking and reflection. The means for the criterion variables found in Table 5 were obtained by summing the items comprising the empirical factor for each of the two scales. As can be seen on the table the relationship between locations (country) and the two criterion variables were significant, however the effect sizes were .03 for systems thinking and .037 for reflecting indicating a small effect.

[Table 5 about here]

A pairwise comparison of the means between location and the criterion variables was conducted to understand the significance of this finding. As seen on Table 6, the Shanghai sample used both reflection and systems thinking skills significantly lower than other locations in the sample. The major distinguishing characteristics of the Shanghai 
respondents were age and gender. Eighty eight percent were female, and one hundred percent of them fell in the 20-25 age category.

[Table 6 about here]

Also noted on Table 6, there were no significant differences between Borneo, KL, and the USA on either scale. However, the USA and Borneo usage of reflection and systems thinking skills usage was significantly greater than Shanghai and HK. The USA and Borneo respondents used systems thinking significantly greater than Shanghai and HK.

Besides a significant difference with Shanghai on both scales, HK produced significantly, lower usage rates compared to Borneo on reflection and Borneo and the USA on the systems thinking scale.

The data from the respondents in two Asian cities differed from the data presented by the respondents in the two Malaysian cities as well as the United States. These significant differences could represent a cultural difference, differences in administration of the STQ, sample size and characteristic differences. To explore an explanation an examination of the influence of age and gender individually and combined on the results for each location.

\subsection{The Effect of Contextual Variables}

The second research question asked if age and gender affect the use of strategic thinking skills. The results on these variables were examined individually, and then their interactions were explored.

\subsection{Gender}

The possible impact of gender on systems thinking and reflection usage scores was analyzed by comparing the differences between male and female respondents. Women totaled fifty-nine percent of the sample. $(\mathrm{N}=193$ versus $\mathrm{N}=135$ ). The univariate analysis of variance displayed on Table 7 indicates that there were no significant differences in the means of systems thinking and reflecting attributed to gender.

[Table 7 about here]

As a comparison of the female and male means on Table 8 indicate that although males reported higher mean scores on reflection and systems thinking usage, there were no significant differences found between the two groups. Thus, the $\mathrm{STQv}^{4}$ seems to be free of gender bias.

[Table 8 about here]

\subsection{Age}

The possible impact of age on strategic thinking skills was tested by comparing the differences among the five age categories - 20-25, 26-34, 35-44, and 45-54. A univariate analysis of variance was conducted. As can be seen on the Table 9, the relationship between age and the two criterion variables was significant and the effect sizes were .151 for systems thinking and 109 for reflecting indicating a moderate effect.

[Table 9 about here]

A comparison of the means between location and the criterion variables was conducted to understand the finding. As seen on Table 10, the age group 20-25 used both reflection and systems thinking skills significantly less than other age categories in the sample. No other significant differences were present in the data. Furthermore, both reflection and systems thinking means rise as age rises.

\section{[Table 10 about here]}

The lowest use of strategic thinking skills was reported significantly less by respondents in the age category 20-25. Reflection ( $M=3.34)$ and systems thinking $(M=3.25)$ rose incrementally from age category 20-25 to age category 45-54 for reflection (M-3.99) and systems thinking $(\mathrm{M}=3.84)$.

In this study, two samples presented respondents in the 20-25 age category. The 51 Shanghai respondents $(100 \%$ of sample) fell into the 20-25 age category. They reported using reflection $(\mathrm{M}=3.08$; SD .488), and systems thinking $(\mathrm{M}=3.01 ; \mathrm{SD}=.406)$ skills. The USA, on the other hand, presented thirty-nine percent (39\%) of its 64 respondents in the 20-25 age category. These respondents reported using reflection $(\mathrm{M}=3.86 ; \mathrm{SD}=.517)$ and systems thinking $(\mathrm{M}=3.75$; $\mathrm{SD}=.487)$. No other site presented respondents in the $20-25$ category.

\subsection{Moderation Effects}

The interactions among location, age, and gender were then explored to determine their effects on usage of systems thinking and reflecting. The interaction of location, gender, age and systems thinking and reflecting produced no significant effects. (See Table 11)

[Table 11 about here] 


\subsection{Summary of Findings}

These analyses indicate that:

(1) Location explains approximately $4 \%$ of the variance in reflection and $3 \%$ of the variance in systems thinking. Examination of the means for each location indicates that Borneo used systems thinking and reflecting skills significantly more than Shanghai and HK. The USA used systems thinking skills significantly more than Shanghai and reflecting significantly more than HK and Shanghai. HK used system thinking significantly more than Shanghai. KL used systems thinking and reflection significantly more than Shanghai. Shanghai used systems thinking and reflecting skills significantly less than all other locations.

(2) Gender produced no significant effects with the use of systems thinking and reflecting skills.

(3) Age explains approximately $11 \%$ of the variance in reflection and $15 \%$ of the variance in systems thinking. Respondents in the age category 20-25 reported using systems thinking and reflecting skills significantly less than all other age categories. No other age category produced significant inter-category effects. The means for both the use of systems thinking and reflecting skills rose from a low use for category 20-25 to higher use for age category 45-54.

(4) The combinations of location, age and gender produced no significant interactions.

\section{Conclusions and Implications}

Three conclusions were drawn from the study.

(1) The improvements in the STQ Version4 have been noteworthy. The reliabilities are stronger than earlier versions. The two subscales (systems thinking and reflection) enable the instrument to be used for predictive studies, and provides a sound factor foundation to continue to validate the reflection subscale. On the results side, we were able to generate firmer confidence in the results found in earlier studies.

This is the first study that directly compared the use of strategic thinking skills as measured by the STQ across different locations. As seen in the previous paragraphs, there were some differences across the different locations. The Borneo and USA samples used the strategic thinking skills to a greater degree than HK and Shanghai but similarly to the KL site. These differences raised several questions that should be addressed in future studies. Were the differences due to the composition of the sample such as Shanghai and the USA? The way the STQ was administered? The Chinese culture compared to the Malay and USA cultures?

(2) One might tend to argue that the difference may not be in level or variance on the factors derived with the complete data set, rather, that the factors themselves are different across cultural groups. With these data, the point may be a good one, but not enough subjects were available to consider cross-cultural factor agreement though separate factor analyses. Our interpretation is that the sample design did not allow comparisons of like samples. Therefore the results seem to be attributed to survey administration and sample make-up not cultural issues.

(3) These data present a potential age bias. Reflection and systems thinking skill usage rose incrementally for each location, as one gets older. (This finding does not apply to Shanghai, which presented all of its 51 respondents into the 20-25 age category and thus could not be analyzed). Rather than an age bias, this 20-25 age category could be a proxy for experience and/or education, which are likely moderators of thinking skills. Is the difference in use of strategic thinking skills due to experience that comes from age or from preparation and degree acquisition? We did not parcel out the age relationship in this way but it would be interesting to do so in another study. What we do see is as age raises so do the use of strategic thinking skills. Our interpretation is that age is a proxy for experience that is gained from work and life and experience that is gained from education. The use of strategic thinking skills most likely is affected by both type of experience; and a practical experience that is supported with a firm educational foundation is probably the best of all worlds. Therefore teaching of these skills in entry college programs as well as throughout the early career years is recommended. Universities should make a significant effort to emphasize strategic thinking as part of their curriculum for students preparing for school leadership positions.

\section{References}

Agor, W. (1988). Finding and developing intuitive managers. Training and Development Journal, 42(3), 68-70.

Argyris, C. \& Schön, D. (1978). Organizational learning: A theory of action perspective. Reading, MA: Addison Wesley. Argyris, C. \& Schön, D. (1996). Organizational learning II: Theory, method and practice. Reading, MA: Addison Wesley.

Baron, J. (1994). Nonconsequentialist decisions. Behavior and Brain Sciences, 17(1), 1-10.

Bertalanffy, L. V. (1968). General system theory: Foundations, development, applications. New York: George Braziller.

Bolman, L. G. \& Deal, T. E. (1994). Looking for leadership: Another search party's report. Educational Administration Quarterly, 30 (1), 77-96.

Bolman, L. G. \& Deal, T. E. (1991). Leadership and management effectiveness: A multi-frame, multi-sector analysis. Human Resource Management, 30, 509-534. 
Chilcoat, R. (1995). Strategic Art: The new discipline for the 21st century. Carslisle, PA: U.S. War College.

Cohen, M., Thompson, B., Adelman, L., Bresnick, T., Shastri, L. \& Riedel, S. (2000). Training critical thinking for the battlefield: Basis in cognitive theory and research. Ft. Leavenworth, KS: U.S. Army Research Institute.

DePree, M. (1989). Leadership is an art. New York: Simon \& Schuster.

Dewey, J. (1933). How we think. Chicago: Henry Regnery.

Halpren, D. (1996). Thought \& knowledge: An introduction to critical thinking. Mahwah, NJ: Lawrence Erlbaum Associates.

Leithwood, K. A. \& Steinbach, R. (1992). Improving the problem-solving expertise of school administrators. Education and Urban Society, 24(3), 317-345.

March, J. G. \& Simon, H. A. (1958). Organizations. New York: Wiley

Mezirow, J. (1990) Fostering Critical Reflection in Adulthood: A Guide to Transformative and Emancipatory Learning .San Francisco: Jossey-Bass Publishers.

Mintzberg, H. (1994) The Rise and Fall of Strategic Planning. New York: Free Press.

Morgan, G. (1986). Images of Organization. Beverly Hills, CA.: Sage.

Newell, A. \& Rosenbloom, P. (1981). Mechanisms of skill acquisition and the law of practice. In J. R. Anderson (Ed.), Cognitive skills and their acquisition. Hillsdale, NJ: Lawrence Erlbaum.

Nunnally, J. C. (1978). Psychometric theory (2 ${ }^{\text {nd }}$ ed.). New York: McGraw-Hill.

Pang, N. S. \& Pisapia, J. (June 2006). The strategic mindset of school leaders in Hong Kong. Paper presented at the 8th Global Leadership Forum, Leadership for Human Development, Istanbul. Turkey.

Peterson, R. (1994). A Meta-Analysis of Cronbach's Coefficient Alpha. The Journal of Consumer Research, 21 (2), 381-391.

Perkins, D. N. (1995). Outsmarting IQ: The emerging science of learnable intelligence. New York: Free Press.

Pisapia, J. (2006). Mastering change in a globalizing world: New directions in leadership (Education Policy Studies Series No. 61). The Hong Kong Institute of Educational Research, The Chinese University of Hong Kong.

Pisapia, J., Reyes-Guerra, D. \& Yasin, M. (2006). Strategic thinking and leader success. Paper presented at the Advances in Management Annual Meeting, Pisbon http://www.pslq.fau.edu/STQ_SLQ_Papers/06Portugal.doc

Pisapia, J., Reyes-Guerra, D. \& Coukos-Semmel, E. (2005). Developing the leader's strategic mindset: Establishing the measures. Leadership Review, 5, 41-68.

Pisapia, J. \& Reyes-Guerra (2008). The Strategic thinking questionnaire: STQv4. Boca Raton, FL: Florida Atlantic University

Riedel, S., Morath, R. \& McGonigle, T. (2000). ARI Workshop Proceedings. Ft. Leavenworth, KS. US Army Research Institute Schön, D. A. (1983). The reflective practitioner: How professionals think in action. New York: Basic Books.

Schreyogg, G. \& Noss, C. (2000). Reframing change in organization: The equilibrium logic and beyond. Academy of Management Proceedings. ODC 2000 Best Paper Award.

Senge, P. M. (1990). The fifth discipline: The art and practice of the learning organization. New York, NY: Doubleday.

Simon, H. A. (1995). Explaining the Ineffable: AI on the Topics of Intuition, Insight and Inspiration. Proceedings of the Fourteenth International Joint Conference on Artificial Intelligence, 1, 939-948.

Simon, H. A. (1957). Administrative behavior (1st ed.). New York: Harper and Row.

Simon, H. A. (1999). The Sciences of the Artificial. Cambridge, MA: MIT Press.

Stanwick, P. (1996). Mental imagery: An alternative to top management team replacement for declining organizations. Journal of Organizational Change Management, 9(2), 47-65.

Usher, R. \& Bryant, I. (1989). Adult Education as Theory, Practice and Research (London: Routledge).

Weick, K. (1995). Sensemaking in organizations. Thousand Oaks, CA: Sage Publications.

Weick, K. \& Quinn, R. (1999). Organization change and development. Annual Review of Psychology, 50, 361-386. 
Table 1. The Demographics of Participants in this Study

\begin{tabular}{|l|l|l|l|l|l|l|l|l|l|l|l|l|l|}
\hline \multicolumn{10}{|l|}{ Location } \\
\hline Gender & Sample & N & $\% *$ & USA & $\% *$ & HK & $\% *$ & KL & $\% *$ & N & $\% *$ & N & $\% *$ \\
Male & 135 & 41 & 9 & 14 & 49 & 48 & 28 & 54 & 6 & 12 & 43 & 73 \\
Female & 193 & 59 & 55 & 86 & 53 & 52 & 24 & 46 & 45 & 88 & 16 & 27 \\
& & & & & & & & & & & & \\
AGE & & & & & & & & & & & & \\
$\mathbf{2 0 - 2 5}$ & 76 & 23 & 25 & 39 & 0 & 0 & 0 & 0 & 51 & 100 & 0 & 0 \\
$\mathbf{2 6 - 3 4}$ & 61 & 18.6 & 23 & 36 & 26 & 26 & 0 & 0 & 0 & 0 & 12 & 20 \\
$\mathbf{3 5 - 4 4}$ & 138 & 42.1 & 14 & 22 & 47 & 46 & 47 & 90 & 0 & 0 & 30 & 59 \\
$\mathbf{4 5 - 5 4}$ & 53 & 16.2 & 2 & 3 & 29 & 28 & 5 & 10 & 0 & 0 & 17 & 29 \\
& & & & & & & & & & & & \\
$\mathbf{N}$ & 328 & 100 & 64 & 20 & 102 & 31 & 52 & 16 & 51 & 16 & 59 & 18 \\
\hline
\end{tabular}

* = percentages may not add to 100 due to rounding of numbers.

Table 2. Means, Standard Deviations and Reliability Coefficients of the Subscales of the Strategic Leadership Questionnaire: Version3, 2007 and Version4, 2008.

\begin{tabular}{|c|c|c|c|c|c|c|c|c|c|c|}
\hline Dimension & Vers & & & & & Vers & & & & \\
\hline & $\underline{\mathbf{M}}$ & $\underline{\text { SD }}$ & $\underline{\mathbf{N}}$ & Alpha & \#items & $\underline{\mathbf{M}}$ & $\underline{\mathbf{S D}}$ & $\underline{\mathbf{N}}$ & Alpha & \#Items \\
\hline $\begin{array}{l}\text { Systems } \\
\text { Thinking } \\
\end{array}$ & 3.55 & .318 & 643 & .713 & 12 & 3.67 & .486 & 330 & .870 & 17 \\
\hline Reframing & 3.45 & .286 & 643 & .777 & 12 & 3.43 & .433 & 330 & .818 & 17 \\
\hline Reflecting & 3.48 & .281 & 643 & .752 & 12 & 3.66 & .416 & 330 & .742 & 14 \\
\hline $\begin{array}{l}\text { Strategic } \\
\text { Thinking }\end{array}$ & 3.50 & .247 & 643 & .891 & 36 & 3.59 & .411 & 330 & .928 & 48 \\
\hline
\end{tabular}

Table 3. Factor Structure (Factor Loadings) for the STQv4. ( $\mathrm{n}=328)$

\begin{tabular}{|l|l|l|l|}
\hline Item \# & Factors & Item \\
\hline & $\begin{array}{l}\text { Systems } \\
\text { Thinking }\end{array}$ & Reflecting & $\begin{array}{l}\text { Stem: } \\
\text { When facing difficult problems, How often do you: }\end{array}$ \\
\hline 4 & $\mathbf{. 7 3 8}$ & .169 & Ask those around you what they think is changing? \\
\hline 6 & $\mathbf{. 5 9 4}$ & & Try to find a common goal when two or more parties are in conflict? \\
\hline 44 & $\mathbf{. 5 4 4}$ & -.167 & $\begin{array}{l}\text { Think about how different parts of the organization influence the way things } \\
\text { are done? }\end{array}$ \\
\hline 24 & $\mathbf{. 5 2 3}$ & & Try to identify external environmental forces which affect your work? \\
\hline 13 & $\mathbf{. 4 2 9}$ & $\mathbf{- . 1 3 8}$ & Engage in discussions with those who hold a different world view? \\
\hline 47 & $\mathbf{. 3 9 7}$ &.- .131 & Define the entire problem before breaking it down into parts? \\
\hline 17 & $\mathbf{. 3 7 0}$ & -.242 & Consider the results of past actions in similar situations? \\
\hline 3 & $\mathbf{. 3 2 1}$ & $\mathbf{- . 1 8 3}$ & Try to extract patterns in the information available? \\
\hline 31 & & $\mathbf{- . 7 9 2}$ & Frame the problems you face in ways that allow you to understand them? \\
\hline 29 & & $\mathbf{- . 6 6 7}$ & $\begin{array}{l}\text { Look at actions being taken to correct the discrepancy between what is } \\
\text { desired and what exists? }\end{array}$ \\
\hline 20 & & $\mathbf{- . 6 4 2}$ & Ask "WHY" questions to develop an understanding of problems? \\
\hline 33 & .206 & $\mathbf{- . 5 5 8}$ & Use different points of view to map out different strategies? \\
\hline 26 & .170 & $\mathbf{- . 5 2 5}$ & $\begin{array}{l}\text { Try to understand how the people in the situation are connected to each } \\
\text { other? }\end{array}$ \\
\hline 32 & .244 & $\mathbf{- . 5 0 1}$ & Look for fundamental long-term corrective measures? \\
\hline
\end{tabular}

Extraction Method: Principal Axis Factoring. Rotation Method: Oblimin with Kaiser Normalization. Rotation converged in 17 iterations. Values less than the 10 threshold were suppressed 
Table 4. Comparison of Means by Location

\begin{tabular}{|l|l|l|l|l|l|l|l|l|l|l|}
\hline & \multicolumn{9}{l}{ Reflection } & \multicolumn{3}{l|}{ Systems Thinking } \\
\hline Location & $\mathrm{M}$ & $\mathrm{SD}$ & $\mathrm{MN}$ & $\mathrm{MX}$ & $\mathrm{N}$ & $\mathrm{M}$ & $\mathrm{SD}$ & $\mathrm{MN}$ & $\mathrm{MX}$ & $\mathrm{N}$ \\
\hline USA & 3.85 & .584 & 2.50 & 4.83 & 64 & 3.85 & .463 & 2.75 & 4.75 & 64 \\
\hline HK & 3.70 & .507 & 2.33 & 4.83 & 102 & 3.53 & .467 & 1.75 & 4.75 & 102 \\
\hline KL & 3.78 & .540 & 1.17 & 4.83 & 52 & 3.66 & .504 & 1.50 & 4.63 & 52 \\
\hline Shanghai & 3.09 & .488 & 1.83 & 4.00 & 51 & 3.01 & .406 & 2.13 & 3.88 & 51 \\
\hline Borneo & 4.00 & 648 & 1.93 & 5.00 & 59 & 3.90 & .500 & 2.25 & 4.75 & 59 \\
\hline Total & 3.70 & .616 & 1.17 & 5.00 & 328 & 3.60 & .551 & 1.50 & 4.75 & 328 \\
\hline
\end{tabular}

Table 5. Test between location and systems thinking and reflecting.

\begin{tabular}{|l|l|l|l|l|l|l|l|l|l|}
\hline & & $\begin{array}{l}\text { Type III } \\
\text { Sum of } \\
\text { Squares }\end{array}$ & df & $\begin{array}{l}\text { Mean } \\
\text { Square }\end{array}$ & F & p & $\begin{array}{l}\text { Partial } \\
\text { Eta } \\
\text { Squared }\end{array}$ & $\begin{array}{l}\text { Noncent. } \\
\text { Parameter }\end{array}$ & $\begin{array}{l}\text { Observed } \\
\text { Power(a) }\end{array}$ \\
\hline Location & Systems Thinking & 2.035 & 3 & .678 & 3.155 & .025 & .030 & 9.466 & .729 \\
\hline Location & Reflecting & 3.434 & 3 & 1.145 & 3.844 & .010 & .037 & 11.532 & .819 \\
\hline
\end{tabular}

A Computed using Alpha $=.05$

Table 6. Comparison of Means for Location and Reflection and Systems Thinking Skill

\begin{tabular}{|c|c|c|c|c|c|c|c|c|}
\hline \multirow[t]{2}{*}{ Location } & \multicolumn{4}{|l|}{ Reflection } & \multicolumn{4}{|c|}{ Systems Thinking } \\
\hline & Location & $\mathrm{MD}^{1}$ & $\mathrm{SE}$ & $\mathrm{p}$ & Location & $\mathrm{MD}$ & $\mathrm{SE}$ & $\mathrm{p}$ \\
\hline \multicolumn{9}{|l|}{ USA } \\
\hline & $\mathrm{HK}$ & .145 & .088 & 1.000 & HK & $.324 *$ & .075 & .000 \\
\hline & KL & .067 & .103 & 1.000 & KL & .192 & .088 & .288 \\
\hline & Shanghai & $.764 *$ & .104 & .000 & Shanghai & $.864 *$ & .088 & .000 \\
\hline & Borneo & -.117 & .100 & 1.000 & Borneo & -.049 & .085 & 1.000 \\
\hline \multicolumn{9}{|l|}{ HK } \\
\hline & USA & .145 & .088 & 1.000 & USA & $-.324 *$ & .075 & .000 \\
\hline & KL & .078 & .094 & 1.000 & KL & -.132 & .080 & 1.000 \\
\hline & Shanghai & $.619 *$ & .095 & .000 & Shanghai & $.522 *$ & .081 & .000 \\
\hline & Borneo & $-.262 *$ & .100 & .040 & Borneo & $-.373 *$ & .077 & .000 \\
\hline \multicolumn{9}{|l|}{$\mathrm{KL}$} \\
\hline & USA & .067 & .103 & 1.000 & USA & -.192 & .088 & .288 \\
\hline & $\mathrm{HK}$ & -.078 & .094 & 1.000 & $\mathrm{HK}$ & .132 & .080 & 1.000 \\
\hline & Shanghai & $.697 *$ & .109 & .000 & Shanghai & $.522 *$ & .093 & .000 \\
\hline & Borneo & -.184 & .105 & .809 & Borneo & -.241 & .089 & .072 \\
\hline \multicolumn{9}{|l|}{ Shanghai } \\
\hline & USA & $.764 *$ & .104 & .000 & USA & $-.846^{*}$ & .088 & .000 \\
\hline & HK & $.619 *$ & .095 & .000 & $\mathrm{HK}$ & $-.522 *$ & .081 & .000 \\
\hline & KL & $.697 *$ & .109 & .000 & KL & $-.654 *$ & .093 & .000 \\
\hline & Borneo & $-.881 *$ & .106 & .000 & Borneo & $-.895 *$ & .090 & .000 \\
\hline \multicolumn{9}{|l|}{ Borneo } \\
\hline & USA & -.117 & .100 & 1.000 & USA & .049 & .085 & 1.000 \\
\hline & HK & $-.262 *$ & .100 & .040 & $\mathrm{HK}$ & $.373 *$ & .077 & .000 \\
\hline & KL & -.184 & .105 & .809 & KL & .241 & .089 & .072 \\
\hline & Shanghai & $-.881 *$ & .106 & .000 & Shanghai & $.895^{*}$ & .090 & .000 \\
\hline
\end{tabular}

Based on estimated marginal means

$1=$ mean difference

*The mean difference is significant at the .05 level.

a. Adjustment for multiple comparisons: Bonferroni 
Table 7. Test between Gender, Systems Thinking and Reflecting

\begin{tabular}{|c|c|c|c|c|c|c|c|c|c|}
\hline Source & Criterion Variable & $\begin{array}{l}\text { Type III } \\
\text { Sum of } \\
\text { Squares }\end{array}$ & $\mathrm{df}$ & $\begin{array}{l}\text { Mean } \\
\text { Square }\end{array}$ & $\mathrm{F}$ & $\mathrm{p}$ & $\begin{array}{l}\text { Partial } \\
\text { Eta } \\
\text { Squared }\end{array}$ & $\begin{array}{l}\text { Noncent. } \\
\text { Parameter }\end{array}$ & $\begin{array}{l}\text { Observed } \\
\text { Power(a) }\end{array}$ \\
\hline Gender & Systems Thinking & .669 & 1 & .669 & 3.114 & .079 & .010 & 3.114 & .421 \\
\hline Gender & Reflecting & .276 & 1 & .276 & .926 & .337 & .003 & .926 & .276 \\
\hline
\end{tabular}

A Computed using Alpha $=.05$

Table 8. Comparison of Means for Gender, Reflection, and Systems Thinking Skills

\begin{tabular}{|l|l|l|l|l|l|l|l|l|l|l|l|l|}
\hline Gender & Reflection & \multicolumn{1}{l|}{ Systems Thinking } \\
\hline & Gender & $\mathrm{M}$ & $\mathrm{SD}$ & $\mathrm{MD}$ & $\mathrm{SE}$ & $\mathrm{p}$ & Gender & $\mathrm{M}$ & $\mathrm{SD}$ & $\mathrm{MD}$ & $\mathrm{SE}$ & $\mathrm{p}$ \\
\hline Male & & 3.77 & .609 & & & & & 3.64 & .564 & & & \\
\hline & Female & & & .133 & .069 & .053 & Female & & & .075 & .062 & .227 \\
\hline Female & & 3.64 & .615 & & & & & 3.57 & .541 & & & \\
\hline & Male & & & -.133 & .069 & .053 & Male & & & -.075 & .062 & .227 \\
\hline
\end{tabular}

${ }^{1}=$ Mean Difference

Based on estimated marginal means

Table 9. Test between Age, Systems Thinking and Reflecting

\begin{tabular}{|c|c|c|c|c|c|c|c|c|c|}
\hline Source & Criterion Variable & $\begin{array}{l}\text { Type III } \\
\text { Sum of } \\
\text { Squares }\end{array}$ & df & $\begin{array}{l}\text { Mean } \\
\text { Square }\end{array}$ & $\mathrm{F}$ & $\mathrm{p}$ & $\begin{array}{l}\text { Partial } \\
\text { Eta } \\
\text { Squared }\end{array}$ & $\begin{array}{l}\text { Noncent. } \\
\text { Parameter }\end{array}$ & $\begin{array}{l}\text { Observed } \\
\text { Power(a) }\end{array}$ \\
\hline Age & Systems Thinking & 11.666 & 4 & 2.916 & 13.570 & .000 & .151 & 54.278 & 1.000 \\
\hline Age & Reflecting & 11.131 & 4 & 2.783 & 9.345 & .000 & .109 & 37.378 & 11.131 \\
\hline
\end{tabular}

a Computed using Alpha $=.05$

Table 10. Comparison of Means for Age, Reflection, and Systems Thinking Skills

\begin{tabular}{|l|l|l|l|l|l|l|l|l|l|l|l|l|}
\hline Age & \multicolumn{1}{l}{ Reflection } & \multicolumn{1}{l|}{ Systems Thinking } \\
\hline & AGE & $\mathrm{M}$ & $\mathrm{SD}$ & $\mathrm{MD}^{1}$ & $\mathrm{SE}$ & $\mathrm{P}^{\mathrm{a}}$ & $\mathrm{AGE}$ & $\mathrm{M}$ & $\mathrm{SD}$ & $\mathrm{MD}$ & $\mathrm{SE}$ & $\mathrm{P}^{\mathrm{a}}$ \\
\hline $20-25$ & & 3.34 & .615 & & & & & 3.25 & .556 & & & \\
\hline & $26-34$ & & & $-392^{*}$ & .100 & .001 & $26-34$ & & & $-390^{*}$ & .089 & .000 \\
\hline & $35-44$ & & & $-422^{*}$ & .083 & .000 & $35-44$ & & & $-430^{*}$ & .074 & .000 \\
\hline & $45-54$ & & & $-651^{*}$ & .104 & .000 & $45-54$ & & & $-586^{*}$ & .092 & .000 \\
\hline $26-34$ & & 3.73 & .601 & & & & & 3.64 & .520 & & & \\
\hline & $20-25$ & & & $.392^{*}$ & .100 & .001 & $20-25$ & & & $.390^{*}$ & .089 & .000 \\
\hline & $35-44$ & & & -.030 & .089 & 1.000 & $35-44$ & & & -.040 & .079 & 1.000 \\
\hline & $45-54$ & & & -.258 & .109 & .110 & $45-54$ & & & -.196 & .097 & .263 \\
\hline $35-44$ & & 3.76 & .566 & & & & & 3.68 & .502 & & & \\
\hline & $20-25$ & & & $.422^{*}$ & .083 & .000 & $20-25$ & & & $.430^{*}$ & .074 & .000 \\
\hline & $26-34$ & & & .030 & .089 & 1.000 & $26-34$ & & & .040 & .079 & 1.000 \\
\hline & $45-54$ & & & -.228 & .094 & .092 & $45-54$ & & & -.156 & .083 & .371 \\
\hline $45-54$ & & 3.99 & .538 & & & & & 3.84 & .485 & & & \\
\hline & $20-25$ & & & $.651^{*}$ & .104 & .000 & $20-25$ & & & $.586^{*}$ & .092 & .000 \\
\hline & $26-34$ & & & .258 & .109 & .110 & $26-34$ & & & .196 & .097 & .263 \\
\hline & $35-44$ & & & .228 & .094 & .092 & $35-44$ & & & .156 & .083 & .371 \\
\hline
\end{tabular}

$1=$ Mean Difference

Based on estimated marginal means

a Adjustment for multiple comparisons: Bonferroni. 
Table 11. Moderation effects between Age (A), Gender (G) and Location (L) in regard to Systems Thinking and Reflecting

\begin{tabular}{|c|c|c|c|c|c|c|c|c|c|}
\hline Source & Criterion Variable & $\begin{array}{l}\text { Type III } \\
\text { Sum of } \\
\text { Squares } \\
\end{array}$ & df & $\begin{array}{l}\text { Mean } \\
\text { Square }\end{array}$ & $\mathrm{F}$ & $\mathrm{p}$ & $\begin{array}{l}\text { Partial } \\
\text { Eta } \\
\text { Squared }\end{array}$ & $\begin{array}{l}\text { Noncent. } \\
\text { Parameter }\end{array}$ & $\begin{array}{l}\text { Observed } \\
\text { Power(a) }\end{array}$ \\
\hline $\mathrm{L} * \mathrm{G}$ & Systems Thinking & .522 & 3 & .174 & .809 & .490 & .008 & 2.427 & .224 \\
\hline $\mathrm{L} * \mathrm{G}$ & Reflecting & 1.186 & 3 & .395 & 1.328 & .265 & .013 & 3.984 & 1.186 \\
\hline $\mathrm{L}^{*} \mathrm{~A}$ & Systems Thinking & .542 & 5 & .108 & .504 & .773 & .008 & 2.520 & .187 \\
\hline $\mathrm{L}^{*} \mathrm{~A}$ & Reflecting & 2.329 & 5 & .466 & 1.565 & .170 & .025 & 7.823 & .545 \\
\hline $\mathrm{G}^{*} \mathrm{~A}$ & Systems Thinking & .633 & 4 & .158 & .737 & .567 & .010 & 2.947 & .237 \\
\hline $\mathrm{G}^{*} \mathrm{~A}$ & Reflecting & 1.800 & 4 & .450 & 1.511 & .199 & .019 & 6.043 & .466 \\
\hline $\mathrm{L} * \mathrm{G} * \mathrm{~A}$ & Systems Thinking & .534 & 3 & .178 & .828 & .480 & .008 & 2.483 & .229 \\
\hline $\mathrm{L} * \mathrm{G} * \mathrm{~A}$ & Reflecting & .555 & 3 & .185 & .621 & .602 & .006 & 1.863 & .179 \\
\hline
\end{tabular}

A Computed using Alpha $=.05$ 